\title{
How to apply remote sensing techniques to precision farming: 2 practical cases by Garnata drone
}

\author{
Javier Rodríguez Utrilla ${ }^{1,}$, Álvaro Nogués Palenzuela ${ }^{1}$, Javier Cabello ${ }^{2}$, Domingo \\ Alcaraz Segura ${ }^{3}$ and Emilio Guirado Hernández ${ }^{4}$ \\ ${ }^{1}$ Agroforestry responsible in Garnata Drone SL. 18013 Granada, Spain \\ 2 Department Biology and Geology. Andalusian Center for Assessment and Monitoring of Global \\ Change, 04120, Almeria, Spain \\ ${ }^{3}$ Department of Botany, University of Granada, 18071, Granada, Spain \\ ${ }^{4}$ Soft Computing and Intelligent Information Systems research group, University of Granada, 18071 \\ Granada, Spain
}

\begin{abstract}
In this report we show 2 different cases in which Remote Sensing can help Precision Farming techniques to optimize and improve profits in the agricultural sector. First, we'll show a practical case in an olive trees field and second an example of how to monitor a greenhouse crop with aerial images and deep learning techniques.
\end{abstract}

\section{Introduction}

Terms like precision agriculture (PA), precision farming, site-specific crop management or even site-specific farming suggest that agricultural management can be practised with high precision. Consequently, PA provides an alternative and realistic means to reduce and optimize the use of potentially harmful compounds and thus can promote a healthier environment for humans [1].

The world's food scenery is changing fast rising the global demand and increasing the cost of agricultural inputs [2]. The adoption of this kind of technology is lower than 5\% usually in countries, therefore is more than $30 \%$ in USA [3].

The general steps of PA practice are data collection, field variability mapping, decision making, and finally management practice. In particular, it is critical to obtain up-to-date images/maps during the process of decision making, thus field variability could be mapped using remotely sensed imagery. Drones play a special role in this field [4].

Hence, it is critical that farmers/Governments know where these variations exist in their fields and so they can adjust their farming practices accordingly [5]. Specifically, changes in remotely sensed reflectance can be detected before symptoms such as infections become visible to the human eye [6]. Because of that, we can advise our clients and calculate terms of productivity, fertilization maps, irrigation studies, early detection of pest/diseases [7], tree counting and damage assessment or automatic detection of areas/species of high

* Corresponding author: jrodriguez@garnatadrone.com 
ecological value for the design of management plans. All the factors that we consider are those that we obtain from the multispectral index generation, as NDVI, NDWI, RVI, RI, GNDVI [9], and we analyze soil and plant, climate and DTM.

Here we present 2 different cases of study to show how this methodology can be adapted to any kind of crop, it can be useful in greenhouse crops too, improving and modernizing the agroforestry sector using the information obtained through remote sensing and changing the traditional farming practices.

\section{Material and Methods}

\subsection{Study Sites}

Two different field trials in Andalusia are included in this report. The first trial (Case A) is an Olive Trees field located in a production farm in the region of "Montes Orientals" in Granada province, Spain $\left(37^{\circ} 23^{\prime} 33.93^{\prime \prime N}, 3^{\circ} 24^{\prime} 40.93\right.$ "O) (Fig. 1).

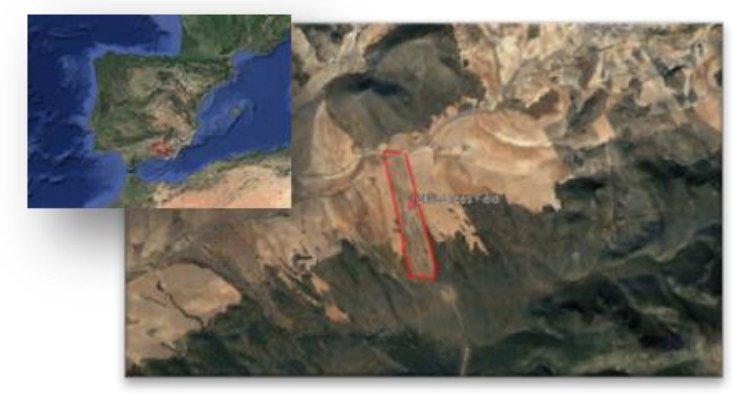

Fig. 1. Study Area and location of olive trees field. Image Source: Google Earth.

The area has 11000 olive trees in 51 hectares of Picual variety, planted in 2006 at $7 \mathrm{~m} \mathrm{x}$ $6 \mathrm{~m}$ with drip irrigation system incorporated.

The second trial (CASE B) are three greenhouses situated in El Ejido, Almeria province $\left(36^{\circ} 44^{\prime} 14.68^{\prime \prime} \mathrm{N}, 2^{\circ} 46^{\prime} 46.21^{\prime \prime} \mathrm{O}\right)$, Spain (Fig. 2). First and second greenhouse with chocolate pepper and last of them cucumber, three in early stages.

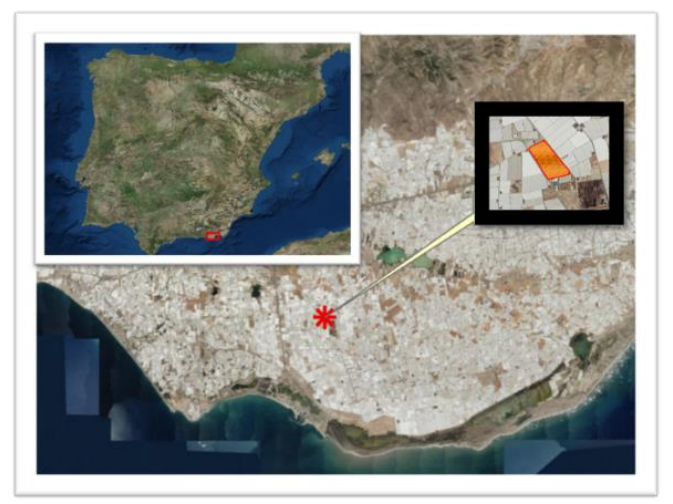

Fig. 2. Study site for case II. Three green houses in EI Ejido, Almeria, Spain. Image Source: ArcGIS. 


\subsection{Image Acquisition and Processing. Analysis overv}

The airborne campaigns were conducted using an UAV Parrot Disco AG Pro with a multispectral camera Parrot Sequoia with 4 different channels, Red, Green, Near Infrared and Red Edge, operated by Garnata Drone SL. The flights were programmed with Pix4D capture software, according to several factors, including the orography, cultivation system, plantation frame, etc.

CASE A) Olive Trees. We plan 2 flights per year, first before Spring (February 2018). We decided to carry out this test prior blooming to evaluate the real status in the crop field and design the amendments which the farmer needs to apply for in order to correct the worst areas. Second flight in Summer (June 2018) during the drought and before the harvest. In this flight we can evaluate the historical status in the olive tree, in case it's necessary to correct the irrigation plan. Finally, also we can check the effect that our recommendations to correct that.

The height was $120 \mathrm{~m}$ and overlap selected was more than $85 \%$ for a ground sample distance (GSD) of $13 \mathrm{~cm} /$ pixel.

CASE B) Green House. We plan a series of multispectral flights with a height of $80 \mathrm{~m}$ an overlap more than $90 \%$ that give us a GSD of $7,13 \mathrm{~cm} /$ pixel. The temporary distance between flights is one month.

With images obtained from the drone, in both cases, we generate ortoimaging processed by Pix4D software (Ecublens, Switzerland) and spectral index maps as NDVI (1), RVI (2), GNDVI (3) and NDWI (4) using SIG software, that allow us to detect affected areas that show high variability in one of those indexes, so we can separate the field into sectors based on the data found, using Object Based Image Analysis (OBIA) and Deep Learning.

$$
\text { NDVI }=\frac{\text { NIR-Red }}{\text { NIR }+ \text { Red }}
$$

where, NIR - Near Infrared, and Red - Red Channel

$$
\begin{aligned}
& \mathrm{RVI}=\frac{\mathrm{NIR}}{\mathrm{Red}} \\
& \text { GNDVI }=\frac{\text { NIR-Green }}{\text { NIR+Green }}
\end{aligned}
$$

where, Green - Green Channel

$$
\mathrm{NDWI}=\frac{\text { Green-NIR }}{\text { Gren+NIR }}
$$

\subsection{Field Measurements}

CASE A) Olive Trees

Once we know the "Problem zones", we can sectorize the field and take samples in areas with low spectral index values to create a complete study of vegetable variables from lab data (soil, water, leaf analysis, fat yield of the olive, etc...) which will explain the causes of anomalies and allow us to treat them in the proper way to optimize the crop productivity. 
We received simultaneously the historical information and data of the crop field and produced an examination of the plantation that details all the necessary information for the decision-making process.

CASE B) Green House

We take Leaf Area Index (LAI) samples in several random points inside the green house (Fig. 3). Every point is measured by submetrical GPS. This measurement must be done at same time we fly UAV, so we can compare spectral image and ground control points/

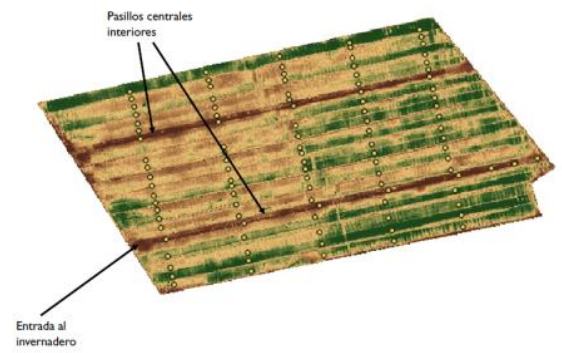

Fig. 3. Yellow points represent measurements of LAI taken by technicians at the same time UAV is flying. Image Source: Andalusian Center for evaluation and assessment of global change-CAESCG, Almeria, Spain.

\section{Results and discussion}

\subsection{Olive Fields}

Using Deep Learning, we generate a classification that allows us to create a database in which each tree is related to the values of the vegetable variables taken into account.

We then recommended amendments to the property owner based on the sectorized maps (Fig. 4) who combined information from spectral index and plant soil samples taken in the problem areas.

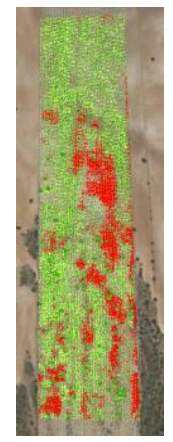

$a$

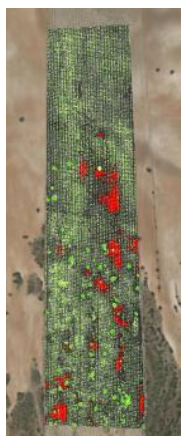

$b$

Fig. 4. Diagnosis map. a) Left February 2018 flight. In red worst areas that needs to be correct. b) Right February 2019 flight, the red zones have decreased after our amendments recommended. Image Source: Garnata Drone SL. 
Below in the Table 1 is a resume of last three years with and without assessment.

\begin{tabular}{|c|c|c|c|}
\hline \multicolumn{5}{|c|}{ The average number of harvest per tree and hectare } \\
\hline Year & Kg per tree & Kg per Hectare & Advice Service \\
\hline 2017 & 18.18 & 3995.60 & No \\
\hline 2018 & 7.27 & 1597.80 & Yes (Start) \\
\hline 2019 & $\mathbf{2 2 . 7 2}$ & $\mathbf{4 9 9 3 . 4 0}$ & Yes \\
\hline \multicolumn{4}{|c|}{ The average of profit per tree and oil per each kg of olive } \\
\hline Year & Oil per each Kg (\%) & Profit per tree (€) & Advice Service \\
\hline 2017 & 22 & 12.72 & No \\
\hline 2018 & 26 & 7.18 & Yes (Start) \\
\hline 2019 & $\mathbf{2 0}$ & $\mathbf{1 4 . 1 9}$ & Yes \\
\hline
\end{tabular}

Table 1. Resume values since 2017 with and without assessment.

\subsection{Green House}

The spectral data taken by drones will be validated with sensors arranged inside the greenhouses and treated by techniques of Object-Oriented Image Analysis (OBIA) and Deep Learning.

This will allow us to identify regions (Fig. 5) of the crop that present anomalies in the value of the greenery of the vegetation. These anomalies are directly related to the elements that can damage the crops. The results will be transferred to the technicians of the company, so that they can be applied to the treatment and monitoring of the status of the crops.

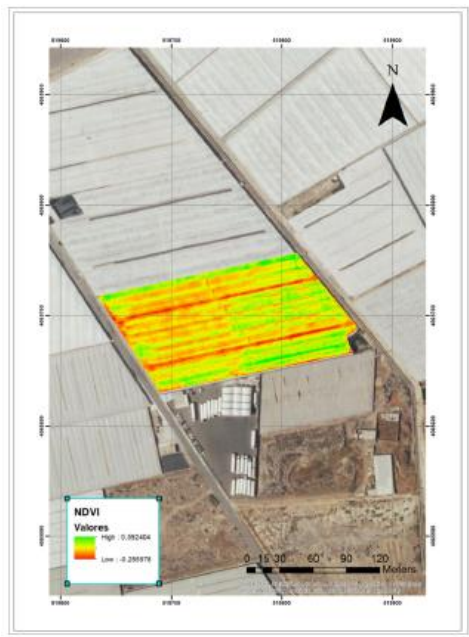

NDVI

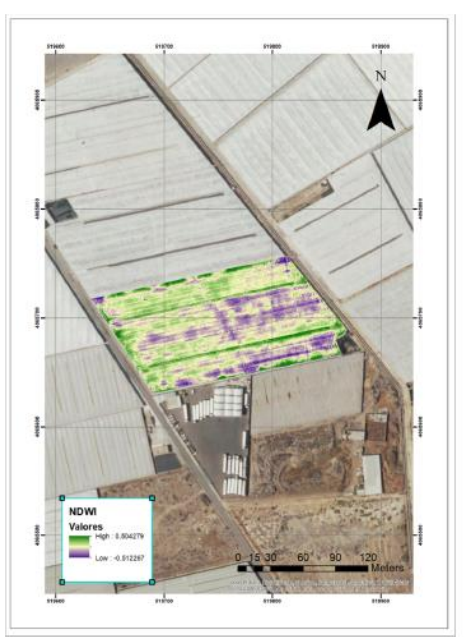

NDWI

Fig. 5. NDVI index in greenhouses (Left) and NDWI index (Right). Clearly the zones were sectorized based on the values of spectral information.

This would allow us to obtain primordial information for the development of monitoring systems for the greenhouses' crops that would have high spatial and temporal precision. 


\section{Conclusion}

The monitoring of crops through spectral images is a reality in the rural world. These types of images, which provide information on functional aspects of the plants, have traditionally been obtained from sensors on satellites. However, spectral images from drones are equally effective and much more affordable.

Applying this methodology either in the open air or in greenhouses allows us to improve the physiological state of the crop by perfecting the application process to different plants and crops of necessary treatments, therefore improving productivity while simultaneously taking part in helping to protect the environment minimizing the inputs of phytosanitary and fertilizers, as we achieve better matching of fertilizer applications to crop yield.

Benefits to society include creation of high technology jobs and mitigation of environmental pollution arising from over - application of nitrogen and other fertilizers.

Therefore, is crucial that producers and scientists work together to create the future agriculture. This method does not replace all other sources of information, but help to improve it.

\section{References}

1. Zhang, Chunhua \& Kovacs, John. The application of small unmanned aerial systems for precision agriculture // A review. Precision Agriculture. 2012. 13. 10.1007/s11119-012-9274-5.

2. R. Kent Crookston. A Top 10 List of Developments and Issues Impacting Crop Management and Ecology During the Past 50 Years. 2016.

3. Santhosh K. Seelan, Soizik Laguette, Grant M. Casady, George A. Seielstad. Remote sensing applications for precision agriculture // A learning community approach. 2003 .

4. Swain, K. C., Thomson, S. J., \& Jayasuriya, H. P. W. Adoption of an unmanned helicopter for lowaltitude remote sensing to estimate yield and total biomass of a rice crop // Transactions of the ASABE, 2010. 53, 21-27

5. Malthus, T. J., \& Maderia, A. C. High resolution spectroradiometry: Spectral reflectance of field bean leaves infected by Botrytis fabae // Remote Sensing of Environment. 1993. 45, 107-116.

6. Chunhua Zhang, John M. Kovacs, The application of small unmanned aerial systems for precision agriculture // A review of Precision Agriculture. 2012. Volume 13, Number 6, Page 693.

7. Anastasiia Safonova, Alexey Rubtsov, Siham Tabik and Domingo Alcaraz-Segura. Application of convolutional neural networks in detection of forest damage caused by the polygraphus proximus beetle // Remote sensing. 2019, 11(6), 643. 